AJChE 2013, Vol. 13, No. 2, 1 - 8

\title{
Predicting of Parameters Affecting on PE Wax Powder Size Distribution and Shape in Atomization Process
}

\author{
Ubonwan Madua ${ }^{1}$ \\ Kulchanat Prasertsit *,1 \\ Paiboon Innachitra ${ }^{1}$ \\ Tanakorn Keatkhunboot ${ }^{1}$ \\ ${ }^{1}$ Department of Chemical Engineering, Faculty of Engineering, Prince of Songkla University, \\ Hat Yai, Songkhla 90112 \\ *e-mail : kulchanat.k@psu.ac.th
}

The aim of this work is to study the parameters affecting on the particle size distribution and shape of Polyethylene wax (PE wax) powders in atomization process. Effect of liquid flow rate, melting temperature and air pressure are studied parameters. External mixing two fluid nozzles is used and temperature is controlled at $200^{\circ} \mathrm{C}$ to avoid freeze-up within the liquid cap. PE wax is melted at various temperatures from $120^{\circ} \mathrm{C}$ to $180^{\circ} \mathrm{C}$ and is atomized with air pressures from 1 to 7 bar. Particle size and size distribution are determined by Particle Sizing Unified System (Mastersizer, 2000). Using 1 bar of air pressure, $140^{\circ} \mathrm{C}$ of melting temperature and 3.0:1.5 of ALR gives the PE wax powders size that smaller than 200 micron and high bulk density. Moreover, smoothly and silky surface of PE wax powders are obtained.

Keywords: Spray drying, Atomization process, Polymer powder, Atomizer, Gas Atomization, Powder size distribution analysis

\section{INTRODUCTION}

In the past few decades, Polyethylene wax (PE wax) powders were increased in variety applications. PE wax powders with diameter range from 5 to $200 \mu \mathrm{m}$ are widely used commercial applications such as paint additive, sprayable coating material and the like. These applications require to the uniform size of PE wax powders for convenient use in the process (wiwax Ltd, 2011).

Process developments of polymer powders in a high capacity at relatively low production costs are interesting. Generally, commercial manufactures of polymer powders use traditional grinding process. However, grinding process has high operating cost due to high energy intensive. Besides that, it sensitively contaminates from grinding equipment. These are reason lead to ensure that, grinding is undesirable powder production process. At present, atomization is the process that producing high quality, spherically shaped of polymer powders 
2 Predicting of Parameters Affecting on PE Wax Powder Size Distribution and Shape in Atomization Process

from molten polymers. The previous research was found that, atomization process is capable and complicated process. The particle size, particle size distribution and shape of polymer powders are controlled by changing relative few input parameters. (Joshua U. Otaigbe and Jon M. Mcavoy, 1997).

Atomization processing unit with two fluid nozzle is showed in Fig. 1(a) and Fig. $1(b)$, respectively. The main parts are divided into three zones such as heating zone, atomizing zone and powder collection zone. Listings of steps in the basic atomization process are including of atomization, liquid-air contact, evaporation and powder collection (particle sizing). A stream of molten polymer is supplied to the atomizing nozzle and is atomized by compress air to disintegrate it to form fine polymer droplets. The atomized polymer droplets fall by gravity and rapidly cool to form solidified polymer particulates that are collected in a collection chamber, e.g. cyclone below the atomizing nozzle (Shjiyuan Ltd, 2011).
Due to atomization process is a singlestep operation from liquid phase to solid phase, many intermediate steps such as crystallizing, filtering, grinding and tableting are completely eliminated. The operating step that strongly effects on the particle size and size distribution is atomizing step. Selecting of nozzle type is also focus in this work. Fig. 1(b) shows the feature of external mixing two fluid nozzles that is used in this study. Liquid cap and air cap diameters are divided in order to reduce energy transfer from compressed air to atomized liquid stream. External mixing two fluid nozzles is able to atomize highly viscous liquid feed. Two advantages are its ability to produce very fine particles and atomize high viscosity fluid (Jim et al, 2010).

\section{EXPERIMENT}

\section{Material}

Thermal properties of PE wax were analyzed by Differential Scanning Calorimeter (DSC method). The melting

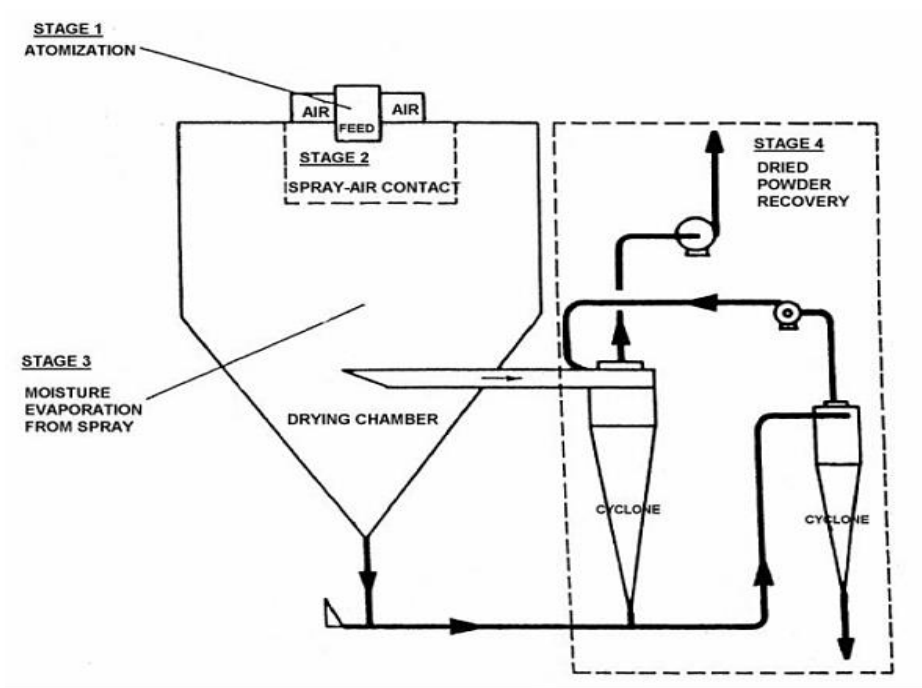

(a)

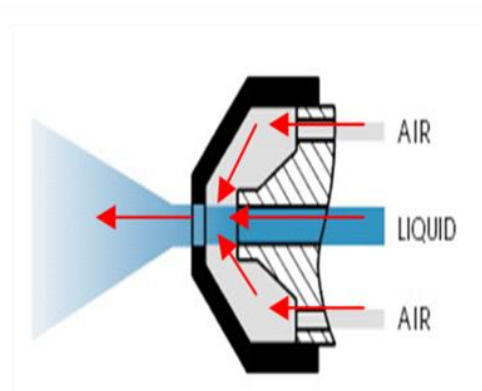

(b)

Fig.1: (a) Atomization process (Sh-jiyuan Ltd, 2011) and (b). Two fluid nozzles 
point and crystallization temperature are $110-120^{\circ} \mathrm{C}$ and $70-80^{\circ} \mathrm{C}$, respectively. $\mathrm{PE}$ wax density is equal to $0.94 \mathrm{~g} / \mathrm{cm}^{2}$. In the experimental, PE wax sample was heated up at various temperatures from 120 to $180^{\circ} \mathrm{C}$. After that, molten PE waxes were atomized by compress air at various pressures from 1 to 7 bars (air at room temperature).

\section{Experimental set up}

Because of this study purpose is to produce the spherical PE wax powders with the size smaller than 200 micron. Effect of air pressure, PE wax melting temperature and feed flow rate in the form of air to liquid ratio (ALR) were the studied parameters.

\section{Study of air pressure effect on PE wax powders}

To study effect of air pressure on PE wax powders, air pressures were varied from 1 to 7 bar. PE wax melting temperature and ALR are fixed at $180^{\circ} \mathrm{C}$ and 3.0:1.5, respectively.

\section{Study of PE wax melting temperature effect on PE wax powders}

Because of melting temperature of PE wax is about 110 to $120^{\circ} \mathrm{C}$, so the melting temperature are varied from 120 to $180^{\circ} \mathrm{C}$. Air pressure and ALR are fixed at 1 bar and 3.0:1.5, respectively.

\section{Study of air to liquid ratio (ALR) effect on PE wax powders}

To study the effecting of air to liquid ratio, air pressure and $\mathrm{PE}$ wax melting temperature are fixed at 1 bar and $140^{\circ} \mathrm{C}$. Ratio of air hole diameter and liquid hole diameter (millimeters) are equal to 1.5: 0.5, 3.0: 0.5, 3.0: 1.0 and 3.0: 1.5 .

\section{Evaluation}

Bulk density and particle size distribution are evaluated for all conditions by Laser diffraction method with Malvern Mastersizer 2000.

\section{RESULTS AND DISCUSSION}

\section{Effect of air pressure on PE wax powders}

The study of effect of air pressure on PE wax powders are showed in Table 1.

From Table 1 , at PE wax melting temperature and ALR equal to $180^{\circ} \mathrm{C}$ and 3.0:1.5, respectively. Atomization with external mixing two fluid nozzle are able to obtain PE wax powders that smaller than 200 micron (-200 micron) up to $90 \% \mathrm{v}$.

Table 1. Particle size distribution and Mean diameters at various air pressure

\begin{tabular}{|c|c|c|c|c|}
\hline \multirow{2}{*}{ Pressure (bar) } & \multicolumn{2}{|c|}{ Volume (\%) } & \multirow{2}{*}{ Mean diameter $(\mathrm{d}(0.5))$} & \multirow{2}{*}{ Span } \\
\hline & -200 micron & +200 micron & & \\
\hline 1 & 92.620 & 7.380 & 78.117 & 2.013 \\
\hline 2 & 99.450 & 0.550 & 77.957 & 1.545 \\
\hline 3 & 100.000 & 0.000 & 59.319 & 1.644 \\
\hline 4 & 99.940 & 0.060 & 60.347 & 1.563 \\
\hline 5 & 97.820 & 2.180 & 56.970 & 1.925 \\
\hline 6 & 92.260 & 7.740 & 92.863 & 1.881 \\
\hline 7 & 98.040 & 1.960 & 57.933 & 1.988 \\
\hline
\end{tabular}


4 Predicting of Parameters Affecting on PE Wax Powder Size Distribution and Shape in Atomization Process

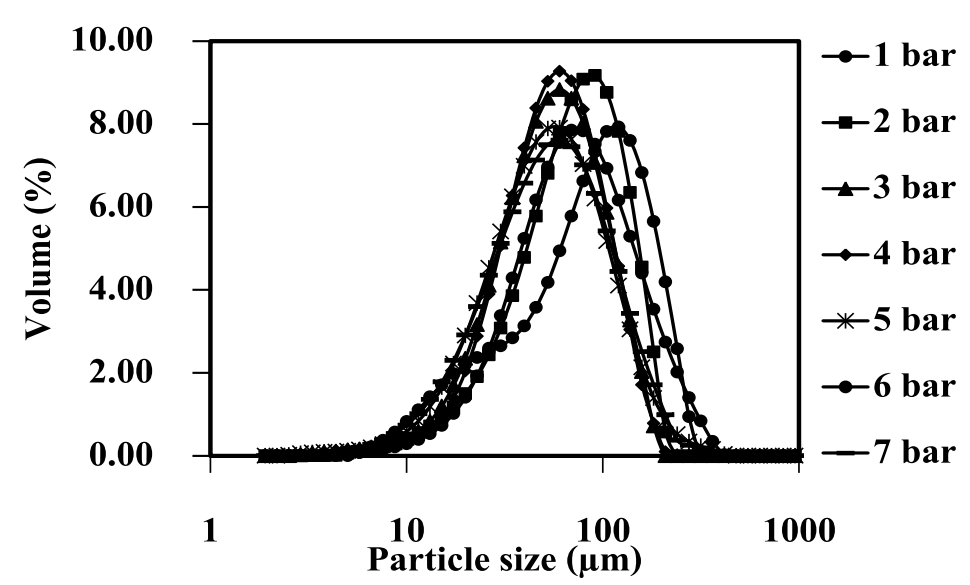

Fig. 2: Particle size distribution of $P E$ wax powders at melting temperature $180^{\circ} \mathrm{C}, 3.0: 1.5$ of ALR with various air pressures

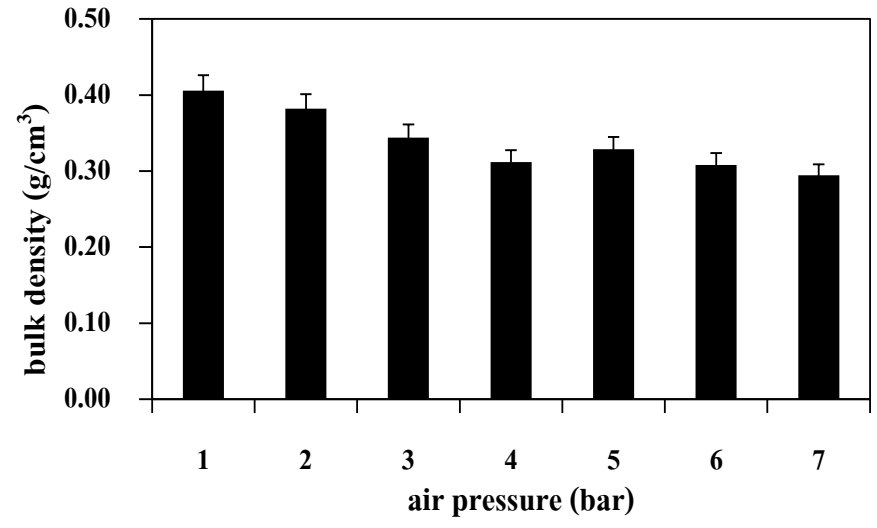

Fig. 3: Bulk density of PE wax powder at melting temperature $180^{\circ} \mathrm{C}, 3.0: 1.5$ of $A L R$ with various air pressures

Fig. 2 shows that, due to PE wax powder size distribution are narrow and has similar trend of each condition. Bulk density of PE wax powders are showed in Fig. 3. It is correlated to void mass and true volume. The experimental found that, bulk density decreases with increasing air pressure. From Fig. 3, 1 bar of air pressure gives the highest bulk density, it can state that the particle has the least void cause the total size of particle of each condition almost the same. However, to ensure that result, bulk density of PE wax powders obtained at melting temperature of 120,140 and $160^{\circ} \mathrm{C}$ are studied. At 1 bar of air pressure remaining gives highest bulk density because using high air pressure allude to high air velocity to atomize melting stream. The higher air velocity achieves more void of PE wax powders.

\section{Effect of melting temperature on PE wax powders}

The experimental varies melting temperature from 120 to $180^{\circ} \mathrm{C}$. The result as show as in Table 2.

Atomization at high temperature (above melting temperature) give the $\mathrm{PE}$ wax powders that smaller than 200 micron (-200 micron) more than low temperature (nearly melting point). Amount of PE wax powders that smaller than 200 micron is up to $90 \% \mathrm{v}$ 
Table 2. PE wax powders size distribution and Mean diameter at various melting temperature

\begin{tabular}{ccccc}
\hline Melting & \multicolumn{2}{c}{ Volume (\%) } & Mean diameter $(\mathrm{d}(0.5))$ & Span \\
\cline { 2 - 3 } temperature $\left({ }^{\circ} \mathrm{C}\right)$ & -200 micron & +200 micron & & 1.69 \\
\hline 120 & 75.2 & 24.80 & 137.0 & 1.70 \\
140 & 85.4 & 14.60 & 112.0 & 1.94 \\
160 & 97.8 & 2.23 & 64.4 & 2.01 \\
180 & 92.6 & 7.38 & 78.1 & \\
\hline
\end{tabular}

that shows in Table 2.

The plot of particle size distribution is showed in Fig. 4. The trends show the narrow size distributions. To ensure the strongly melting temperature that proper up in this experimental, clearly results are showed in Fig. 5. The plot is intuitively satisfying as shows the bulk density of PE wax powders are approximately. Bulk density of PE wax powders are decrease when increasing melting temperature. Highest bulk density is obtained when atomized at $140^{\circ} \mathrm{C}$ of melting temperature. The experimental found that, when the

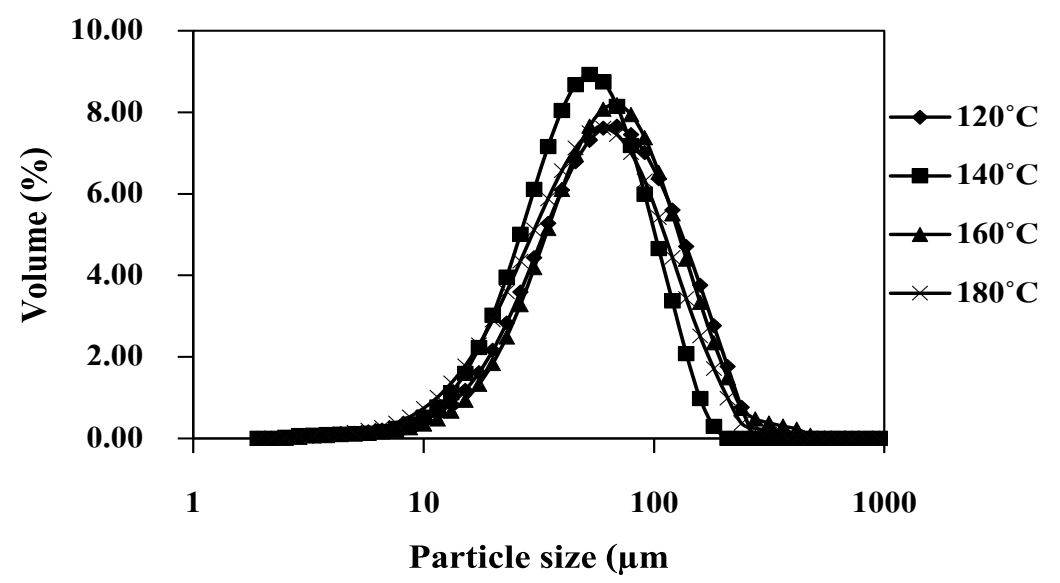

Fig. 4: Particle size distribution of PE wax powder with 1 bar of air pressure, 3.0:1.5 of ALR at various melting temperatures

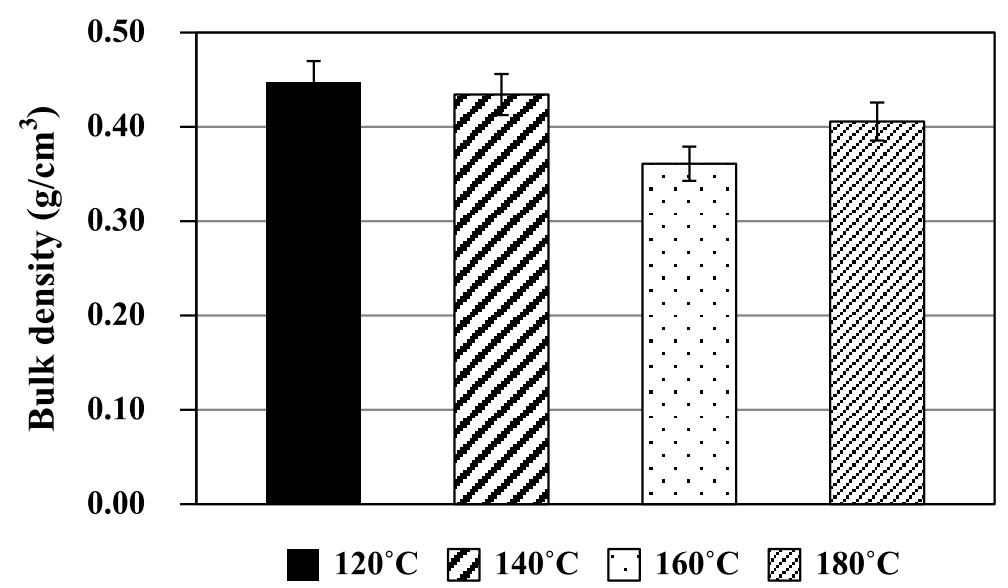

Fig. 5: Bulk density of PE wax powder with 1 bar of air pressure, 3.0:1.5 of ALR at various melting temperature 
6 Predicting of Parameters Affecting on PE Wax Powder Size Distribution and Shape in Atomization Process

operation atomizes with high melting temperature, melting stream can split easily and achieve more void of PE wax powders.

\section{Effect of air to liquid ratio (ALR) on PE wax powders}

Due to ALR at 1.5:0.5 is too small, feed flow rate precariously obstructs within the nozzle and cannot collect PE wax powders from this condition. Therefore, this ALR is impracticable condition. Table 3 found that, all state of ALR can obtain PE wax powders that smaller than 200 micron above $85 \% \mathrm{v}$ and nearby particle size distribution. The plots of particle size distribution are show in Figure 6.

ALR is a strongly parameter on atomization process. Fig. 6 shows the similar particle size distributions. Clearly result is shown in Fig. 7. The plot of PE wax's bulk density at each ALR is showed. Various ALR gives distinct bulk density. At ALR equal to 3.0:1.5 gives a highest bulk density. When the operations using high ALR that mean high amount of compress air feed into the nozzle cause to makes void PE wax powders.

Feature of PE wax powders shape and surface analyzed by the optical microscope $(\mathrm{OM})$ is shown in Fig. 8. Spherical shape and silky surface are obtained from this condition $\left(140^{\circ} \mathrm{C}, 1\right.$ bar of air pressure and 3.0:1.5 of ALR).

Table 3. PE wax powders size distribution and Mean diameter at various melting temperature

\begin{tabular}{ccccc}
\hline \multirow{2}{*}{ ALR } & \multicolumn{2}{c}{ Volume $(\%)$} & \multirow{2}{*}{ Mean diameter $(\mathrm{d}(0.5))$} & Span \\
\cline { 2 - 3 } & -200 micron & +200 micron & & \\
\hline $3.0: 0.5$ & 93.7 & 6.30 & 33.3 & 3.84 \\
$3.0: 1.0$ & 98.3 & 1.72 & 48.6 & 2.37 \\
$3.0: 1.5$ & 85.4 & 14.60 & 112.0 & 1.70 \\
\hline
\end{tabular}

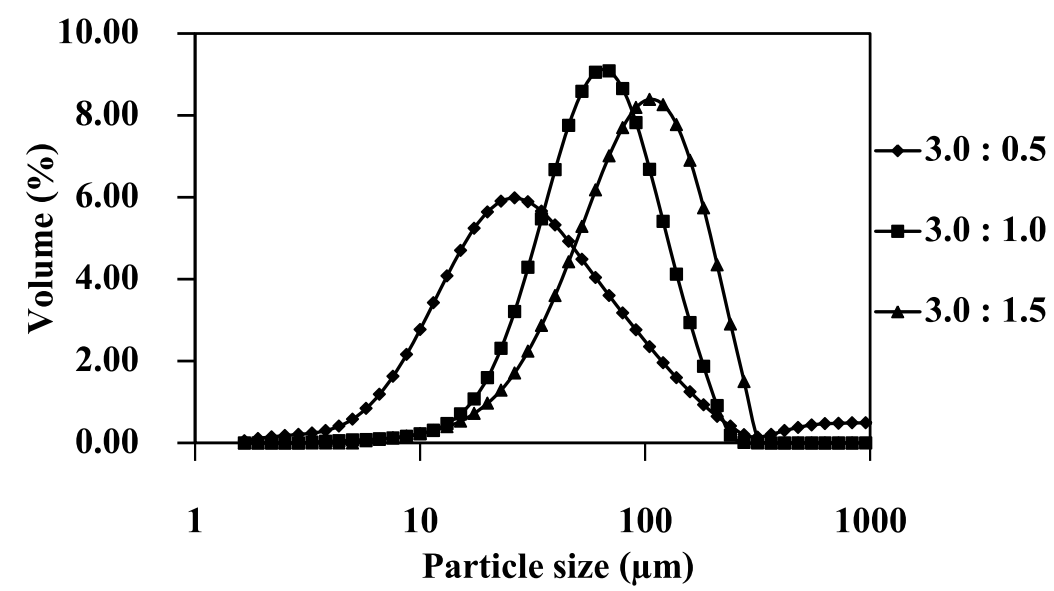

Fig. 6: Particle size distributions of $P E$ wax powders with $140^{\circ} \mathrm{C}$ of melting temperature, 1 bar of air pressure at various ALR 


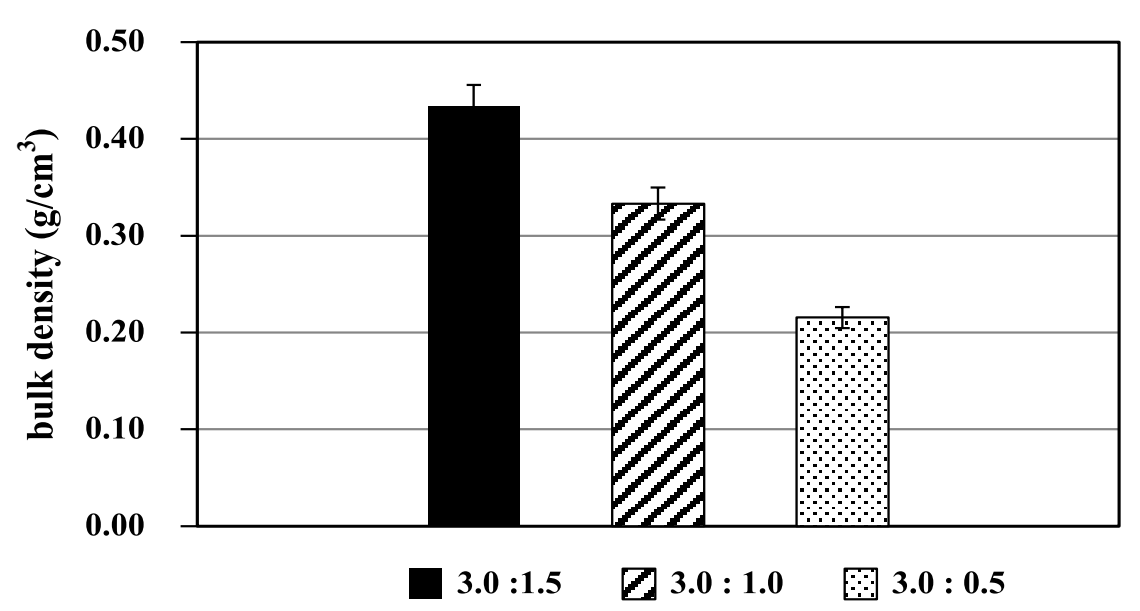

Fig. 7: Bulk density of PE wax powder at various ALR

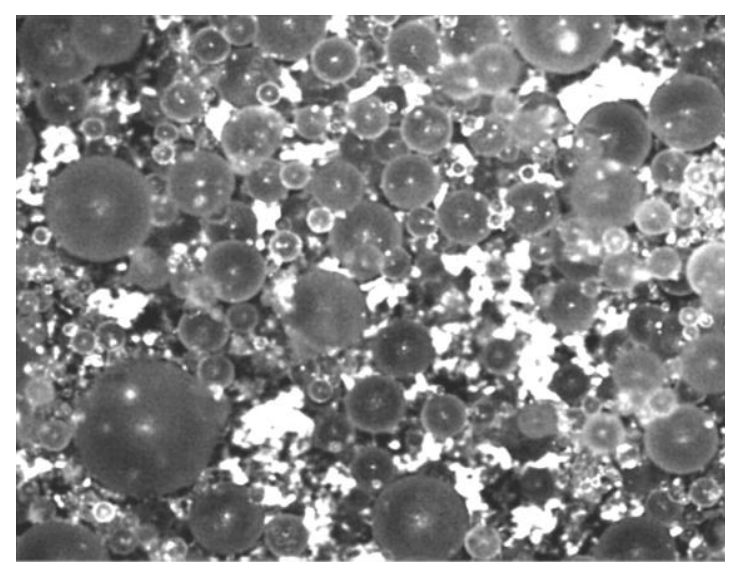

Fig. 8: Photograph of PE wax powder that obtain in this atomization process with $140^{\circ} \mathrm{C}, 1$ bar of air pressure and $3.0: 1.5$ of ALR

\section{CONCLUSIONS}

1) Similar particle size is obtained in this study at various air pressures. The experimental find that, bulk density is distinct obviously. Low air pressure gives high bulk density of PE wax powders.

2) Atomization at melting temperature from 120 to $180^{\circ} \mathrm{C}$ is able to produce 200 micron up to $85 \% \mathrm{v}$ and bulk density is satisfyingly if using nearby melting point temperature of $\mathrm{PE}$ wax.

3) High ALR that means high amount of compress air flow into the nozzle and achieve more void of PE wax powders. Mostly -200 micron of PE wax powders are obtained with various ALR.

Relevant strongly parameters such as air pressure, melting temperature and feed flow rate in atomization process are still interesting parameters because of mostly industries require fine particle and high bulk density for comfortable transport and packaging.

\section{ACKNOWLEDGEMENT}

The authors gratefully acknowledge the NSTDA University Industry Research Collaboration, (NUI-RC), IRPC Public Company Limited for financial support. And Department of Chemical Engineering under Faculty of Engineering, Prince of Songkla University Thailand for their help and advice during this study. 
8 Predicting of Parameters Affecting on PE Wax Powder Size Distribution and Shape in Atomization Process

\section{REFERENCES}

1. Otaigbe, J.U. and J.M. McAvoy. (1998). Gas atomization of polymers. I. Feasibility studies and process development. Advances in Polymer Technology, 17(2): p. 145-160.

2. Wiwax. LTD. (2011). PE wax applications. Available from: http://www/wiwax.eu/en/main.php?k0 $=$ APPLICATIONS. Accessed June 2011.

3. Sh-jiyuan Ltd. (2011). Spray drying manual. Avairable from: http://www.shjiyuan.com/download/01/SDX_MANUA L.PDF. Accessed June 2011.

4. Ejim, C.E., Rahman, M.A., Amirfazli, A. and Bleck, B.A.( 2010). Effects of liquid viscosity and surface tension on atomization in two-phase, gas/liquid fluid coker nozzles. Fuel. 89(8): p. 18721882. 